\title{
Perfil de susceptibilidade a antimicrobianos de bactérias isoladas em diferentes sistemas de cultivo de tilápia-do-nilo (Oreochromis niloticus)
}

\author{
[Profile of antimicrobial resistance in bacterial populations recovered from different Nile tilapia \\ (Oreochromis niloticus) culture systems] \\ D.O. Carneiro ${ }^{1}$, H.C.P. Figueiredo ${ }^{*}$, D.J. Pereira Júnior ${ }^{1}$, \\ C.A.G. Leal ${ }^{1}$, P.V.R. Logato ${ }^{2}$ \\ ${ }^{1}$ Departamento de Medicina Veterinária - UFLA \\ Caixa postal 37 \\ 37200-000 - Lavras, MG \\ ${ }^{2}$ Departamento de Zootecnia - UFLA - Lavras, MG
}

\begin{abstract}
RESUMO
Caracterizaram-se as populações bacterianas isoladas de três sistemas de cultivo de tilápias, sem utilização prévia de antimicrobianos. No sistema 1 usou-se tanque de alvenaria com arraçoamento, no sistema 2, tanque de terra com arraçoamento e no sistema 3, tanque de terra com adubação orgânica. Posteriormente, foi verificado o perfil qualitativo de resistência a antimicrobianos de 98 amostras bacterianas. Membros da família Vibrionaceae predominaram nos três sistemas analisados. Observou-se elevado número de bactérias resistentes principalmente à ampicilina e à eritromicina. Bactérias resistentes à norfloxacina e à gentamicina não foram freqüentes e cerca de $50 \%$ das amostras dos isolados bacterianos foram resistentes à tetraciclina. Dentre as amostras testadas, $96 \%$ apresentaram resistência simultânea a dois ou mais antimicrobianos (MAR $>0,2$ ). O índice MAR médio para os três sistemas de criação foi 0,4 , e foram mesmo considerados fontes de risco para disseminação de bactérias resistentes.
\end{abstract}

Palavras-chave: tilápia-do-nilo, antimicrobianos, bactérias

\begin{abstract}
Bacterial populations from different tilapia culture system with no antimicrobial use were characterized. Concret pond and commercial feed, land pond and commercial feed, and land pond and animal manure were used in systems I, II and III, respectively. Ninety-eight bacterial strains were subjected to sensitivity testing. Members of Vibrionaceae were the most prevalent in all systems analysed. The most bacterial strains were resistant to ampicillin and erithromicin, but resistance to norfloxacin and gentamicin were uncommon. A half to bacterial isolates was resistant to tetracycline. From the 98 bacterial isolates, $96 \%$ were resistant to two or more antimicrobials. The multiple antimicrobial resistance index was determined and it was similar for all systems analyzed (Mar=0.4), indicating a high risk source for multiple antibiotic resistance.
\end{abstract}

Keywords: nile tilapia, antibiotic, bacteria, antimicrobial resistance

\section{INTRODUÇÃO}

O amplo uso de antibióticos na medicina humana e na produção animal tem resultado no aumento do número de bactérias comensais e patogênicas resistentes a agentes antimicrobianos, o que vem se tornando um dos principais problemas de saúde pública (Sorum e Abée-Lund, 2002; Rivera-Tapia, 2003). Bactérias resistentes a antibióticos são encontradas em diferentes nichos ecológicos. Dentre esses nichos, o ambiente aquático é considerado como o mais eficiente

Recebido em 22 de julho de 2005

Aceito em 17 de maio de 2007

* Autor para correspondência (corresponding author)

E-mail: henrique@ufla.br 
para a seleção de populações bacterianas resistentes, bem como para a troca de genes de resistência, por meio de elementos genéticos móveis (Ali Abadi e Lees, 2000; Wegener e Moller, 2000).

Antibióticos agem como indutores para expressão de genes bacterianos que codificam mecanismos de resistência às drogas (Butaye et al., 2003). Assim, na presença de genes de resistência, a seleção de uma população de microrganismos resistentes pode ser uma conseqüência da pressão de seleção devido ao uso de antibióticos. O poder de seleção é proporcional ao tempo de exposição das bactérias ao antibiótico (Ali Abadi e Lees, 2000).

O uso profilático de antibióticos na aqüicultura tem-se tornado comum, principalmente em países em desenvolvimento, onde não há regulamentação para o uso de drogas em ambientes aquáticos. Assim, muitos produtores ignoram que o uso indiscriminado de antibióticos proporciona, dentre os principais riscos, a seleção de bactérias resistentes no ambiente aquático, a alteração da microbiota dos ambientes de cultivo e a transferência de resistência para bactérias potencialmente patogênicas aos seres humanos (Hölmstrom et al., 2003). Portanto, o uso de antibióticos na aqüicultura deve ser limitado, a fim de se reduzir a disseminação de resistência aos mesmos entre bactérias patogênicas ou da flora comensal de peixes e de outros organismos cultivados, além de evitar o risco da presença de resíduos nos alimentos destinados ao consumo humano (Bruun et al., 2003).

Diferentes sistemas são utilizados para o cultivo do pescado no Brasil, como por exemplo, os constituídos por tanques de alvenaria ou de terra. $\mathrm{O}$ tanque de alvenaria pode reduzir a contaminação do pescado, visto que o solo apresenta grande diversidade de microrganismos que podem levar à elevada densidade de populações bacterianas presentes no ambiente de cultivo. Porém, tanques de alvenaria elevam a dureza da água e, por isso, são menos utilizados. Outra fonte de contaminação do ambiente de cultivo do pescado é a utilização de dejetos de animais para adubação dos tanques de criação, a fim de reduzir os custos de produção, promovendo o desenvolvimento do plâncton, que serve de alimento natural para peixes filtradores, como a tilápia. Os excrementos de animais podem carrear resíduos de antibióticos ou bactérias resistentes a essas drogas para $o$ ambiente aqüícola. A presença de resíduos de antibióticos favorece a seleção de bactérias resistentes que podem se inserir na cadeia alimentar humana por meio do pescado contaminado e transferir genes de resistência às bactérias da microbiota indígena ou potencialmente patogênicas para seres humanos (Ostrensky e Boeger, 1998; Petersen et al., 2002; Petersen e Dalsgaard, 2003a).

Poucos estudos, entretanto, têm caracterizado a presença de bactérias resistentes em ambientes aqüícolas sem uso prévio de antibióticos. Além disso, o potencial de cada um dos sistemas de cultivo, em relação à capacidade de albergar bactérias resistentes a antibióticos e contribuir para disseminação de genes bacterianos de resistência, ainda não está bem estabelecido. Os objetivos deste trabalho foram caracterizar e determinar o perfil de resistência a antimicrobianos de populações bacterianas isoladas em três diferentes sistemas de cultivo de tilápia-do-nilo (Oreochromis niloticus, Linnaeus 1758), sem utilização prévia de antibióticos, constituídos por tanque de alvenaria ou de terra, com adubação orgânica ou não.

\section{MATERIAL E MÉTODOS}

Foram selecionados três sistemas de cultivo de tilápia-do-nilo, sem utilização prévia de antibióticos, contemporâneos e localizados na mesma propriedade, e povoados simultaneamente. O Sistema 1, constituído por tanque de alvenaria, utilizou ração comercial extrusada para fase de engorda com $28 \%$ de proteína bruta. O Sistema 2, constituído por tanque de terra escavado, utilizou a mesma ração do Sistema 1. O arraçoamento nesses dois sistemas foi realizado duas vezes ao dia. O Sistema 3 foi constituído por tanque de terra escavado com adubação e sem arraçoamento. A fertilização nesse sistema foi realizada antes de seu povoamento, por meio da adição de adubo orgânico e inorgânico. Como adubo orgânico utilizou-se excreta de aves submetida previamente à compostagem. Uma mistura de sulfato de amônia e superfosfato simples, para manter a relação nitrogênio:fósforo de 5:1, foi utilizada para adubação inorgânica. Além disso, a manutenção foi realizada mediante adição 
quinzenal de adubo orgânico ao tanque de cultivo do sistema 3 .

Os tanques, utilizados previamente para o cultivo de tilápia-do-nilo, antes do início do experimento, foram secados, para receber calagem (exceto o tanque de alvenaria) e, seqüencialmente, serem povoados com os peixes.

Para análise de cada sistema, coletou-se simultaneamente a água dos tanques e três peixes, com peso médio de 300 gramas. A água de cultivo foi coletada em três diferentes pontos do tanque, cerca de 30 centímetros abaixo da superfície da lâmina de água. As amostras de água foram acondicionadas em frascos estéreis e enviadas ao laboratório à temperatura ambiente, onde foram imediatamente processadas. Os peixes foram capturados ao acaso e enviados ao laboratório. No laboratório, os peixes foram sacrificados por choque térmico, conforme recomendado por Noga (1996), e foram submetidos à metodologia da rinsagem ou lavagem superficial (Harrigan, 1998). Posteriormente, realizou-se a coleta asséptica do conteúdo intestinal.

As amostras coletadas foram submetidas a diluições seriadas, para obtenção de colônias isoladas. Alíquotas de $0,1 \mathrm{ml}$ das diluições adequadas foram semeadas, segundo o método de espalhamento na superfície, em ágar soja tripticaseína $^{1}$ (TSA), suplementado com nistatina $^{2}(1000 \mathrm{UI} / \mathrm{ml})$, a fim de reduzir a contaminação das placas por leveduras e fungos filamentosos. As placas semeadas foram incubadas a $30^{\circ} \mathrm{C}$ durante 24 horas. Após o período de incubação, as colônias de diferentes morfotipos, oriundas das placas que apresentaram colônias isoladas de cada amostra, foram selecionadas e repicadas em TSA. Os isolados foram submetidos aos testes de Gram, catalase, oxidase e oxidação-fermentação (O-F) para a identificação das famílias bacterianas (Quinn et al., 1994).

Dentre os isolados bacterianos identificados, 98 representantes foram submetidos à determinação do perfil qualitativo de resistência a antibióticos, por meio do método de difusão de discos de

${ }^{1}$ Biolife - Itália

${ }^{2}$ Teuto - Brasil antibióticos, utilizando-se ágar Mueller-Hinton ${ }^{3}$ (Performance..., 1990). Os antibióticos selecionados para realização dos testes foram: ampicilina $(10 \mu \mathrm{g})$, cefuroxima $(30 \mu \mathrm{g})$, cloranfenicol $(30 \mu \mathrm{g})$, eritromicina $(5 \mu \mathrm{g})$, gentamicina $(10 \mu \mathrm{g})$, nitrofurantoína $(300 \mu \mathrm{g})$, norfloxacina $(10 \mu \mathrm{g})$, tetraciclina $(30 \mu \mathrm{g})$ e sulfonamidas $(300 \mu \mathrm{g})$. Foram utilizadas, como controle de qualidade do teste, as amostras de referência Pseudomonas aeruginosa (ATCC 27853) e Staphylococcus aureus (ATCC 25923). Por meio de swabs estéreis, as amostras selecionadas foram estriadas em placas de petri com ágar Mueller-Hinton. Os discos de antibióticos ${ }^{4}$ foram colocados na superfície do ágar, utilizando-se pinças previamente flambadas. As placas foram incubadas a $30^{\circ} \mathrm{C}$ durante 18-24 horas. Após a incubação, os diâmetros dos halos de inibição foram mensurados e comparados com a tabela de performance padrão para testes de susceptibilidade a antibióticos e, então, as bactérias foram classificadas como sensíveis ou resistentes.

$\mathrm{O}$ índice MAR (múltipla resistência antimicrobiana) foi utilizado para determinação da múltipla resistência. Este índice, quando aplicado a um isolado bacteriano, é definido como $\mathrm{a} / \mathrm{b}$, ou seja, o número de antibióticos aos quais o isolado foi resistente (a) dividido pelo número de antibióticos aos quais o isolado foi exposto (b). Índice MAR acima de 0,2 caracteriza multirresistência (Krumperman, 1983).

\section{RESULTADOS}

Os dados da Tab. 1 representam o número de membros das famílias bacterianas identificadas, presentes nos sistemas de cultivo analisados. No sistema 1, foi isolado maior número de membros da família Vibrionaceae. No sistema 2, predominaram as famílias Pseudomonadaceae, Vibrionaceae e Enterobacteriaceae. No 3, apesar da adubação orgânica, houve menor isolamento de membros da família Enterobacteriaceae, com predomínio de bactérias das famílias Vibrionaceae e Micrococcaceae. Todos os membros da família Micrococcaceae isolados pertenciam ao gênero Staphylococcus sp. De modo geral, a família mais prevalente nos

${ }^{3}$ Oxoid - EUA

${ }^{4}$ Cecon - Brasil 
sistemas de criação analisados foi a Vibrionaceae, que é considerada parte da microbiota natural de ambientes aquáticos. Além disso, verificou-se que parte das amostras bacterianas não se enquadrou em nenhuma das famílias descritas, visto que o ambiente aquático possui grande diversidade de espécies bacterianas (Miranda e Zemelman, 2002).

Tabela 1. Freqüência e identificação de amostras bacterianas obtidas de diferentes sistemas de cultivo de tilápia-do-nilo (Oreochromis niloticus)

\begin{tabular}{lcccc} 
& \multicolumn{3}{c}{ Sistema de cultivo } & \multirow{2}{*}{ Total } \\
\cline { 2 - 4 } \multicolumn{1}{c}{ Família } & Sistema 1 & Sistema 2 & Sistema 3 & 45 \\
Enterobacteriaceae & $16(10 \%)$ & $25(15 \%)$ & $4(2,0 \%)$ & 87 \\
Micrococcaceae & $13(8,0 \%)$ & $18(10 \%)$ & $56(23 \%)$ & 65 \\
Pseudomonadaceae & $18(12 \%)$ & $27(16 \%)$ & $20(9,0 \%)$ & 115 \\
Vibrionaceae & $32(20 \%)$ & $25(15 \%)$ & $58(23 \%)$ & 261 \\
Não identificadas & $80(50 \%)$ & $78(44 \%)$ & $103(43 \%)$ & 573 \\
\hline Total & 159 & 173 & 241 & \\
\hline
\end{tabular}

Sistema 1: tanque de alvenaria com arraçoamento; Sistema 2: tanque de terra com arraçoamento; Sistema 3: tanque de terra com adubação orgânica.

Os percentuais de bactérias resistentes, isoladas dos sistemas de cultivo 1,2 e 3 , aos antibióticos testados pelo método de discos de difusão são apresentados na Tab. 2. De modo geral, observase que os perfis de resistência das amostras bacterianas entre os sistemas de criação analisados foram semelhantes, o que sugere que a alimentação das tilápias e o tipo do tanque de cultivo não influenciaram o perfil de resistência dos microrganismos. As bactérias apresentaram freqüências de resistência isoladas consideradas elevadas, apresentando-se resistentes principalmente à ampicilina ( $\beta$-lactâmico) e à eritromicina (macrolídeo). Menores porcentagens de resistência foram verificadas para norfloxacina (quinolona) e gentamicina (aminoglicosídeo). Além disso, cerca de 50\% das amostras bacterianas foram resistentes à tetraciclina.

Tabela 2. Freqüências de resistência a antimicrobianos em amostras bacterianas, oriundos de diferentes sistemas de cultivo de tilápia-do-nilo (Oreochromis niloticus)

\begin{tabular}{lccc}
\hline \multirow{2}{*}{ Antibióticos } & \multicolumn{3}{c}{ Número de amostras resistentes (\%) } \\
\cline { 2 - 4 } Ampicilina & Sistema 1 & Sistema 2 & Sistema 3 \\
Cefuroxima & $23(72 \%)$ & $24(73 \%)$ & $22(67 \%)$ \\
Cloranfenicol & $9(28 \%)$ & $17(51 \%)$ & $15(45 \%)$ \\
Eritromicina & $7(22 \%)$ & $10(30 \%)$ & $9(27 \%)$ \\
Gentamicina & $26(81 \%)$ & $25(78 \%)$ & $28(85 \%)$ \\
Nitrofurantoína & $2(6 \%)$ & $2(6 \%)$ & $5(15 \%)$ \\
Norfloxacina & $9(28 \%)$ & $13(39 \%)$ & $12(36 \%)$ \\
Sulfonamidas & $8(25 \%)$ & $2(6 \%)$ & $6(18 \%)$ \\
Tetraciclina & $18(56 \%)$ & $13(39 \%)$ & $12(36 \%)$ \\
\hline
\end{tabular}

Sistema 1: tanque de alvenaria com arraçoamento; sistema 2: tanque de terra com arraçoamento; sistema 3: tanque de terra com adubação orgânica.

Número total de isolados bacterianos: 32 (sistema 1), 33 (sistema 2) e 33 (sistema 3).

A resistência aos antibióticos testados, de acordo com as famílias identificadas nos diferentes sistemas de cultivo analisados, está apresentada na Tab. 3. Dentre as famílias analisadas, verificase maior número de isolados resistentes à ampicilina e à eritromicina nas famílias Pseudomonadaceae e Vibrionaceae. A família Pseudomonadaceae apresentou freqüência de resistência mais alta a um grande número de antibióticos testados (eritromicina, cefuroxima, cloranfenicol, ampicilina e nitrofurantoína). Além disso, bactérias resistentes à norfloxacina $\mathrm{e}$ à tetraciclina foram mais freqüentes na família Micrococcaceae, enquanto a resistência à gentamicina foi rara em todas as famílias analisadas. 
Tabela 3. Perfil de resistência a antibióticos em amostras bacterianas de diferentes famílias, oriundas de três sistemas de cultivo de tilápia-do-nilo (Oreochromis niloticus)

\begin{tabular}{lccccccccccc}
\hline \multirow{1}{*}{ Famílias } & \multicolumn{10}{c}{ Antibiótico } \\
\cline { 2 - 11 } & $\begin{array}{c}\mathrm{N}^{\mathbf{0}} \text { de } \\
\text { amostras }\end{array}$ & NOR & TET & ERI & CFX & CLO & AMP & GEN & SUL & NIT \\
\hline Enterobacteriaceae & 17 & 1 & 5 & 17 & 8 & 3 & 14 & 1 & 5 & 6 \\
Micrococcaceae & 21 & 10 & 19 & 7 & 1 & 0 & 3 & 0 & 12 & 2 \\
Pseudomonadaceae & 21 & 2 & 13 & 21 & 20 & 16 & 20 & 2 & 3 & 20 \\
Vibrionaceae & 21 & 0 & 4 & 20 & 2 & 0 & 20 & 4 & 19 & 0 \\
Não identificadas & 18 & 3 & 9 & 14 & 10 & 7 & 12 & 2 & 4 & 6 \\
\hline Total & 98 & 16 & 50 & 79 & 41 & 26 & 69 & 9 & 43 & 34 \\
\hline
\end{tabular}

Nor: Norfloxacina, TET: tetraciclina, ERI: eritromicina, CFX: cefuroxima, CLO: cloranfenicol, AMP: ampicilina, GEN: gentamicina, SUL: sulfonamidas, NIT: nitrofurantoína.

O índice de múltipla resistência (MAR) aos antimicrobianos testados foi determinado em relação às famílias bacterianas identificadas, como pode ser observado na Tab. 4. Dentre as 98 amostras bacterianas testadas, $96 \%$ apresentaram índice MAR igual ou acima de 0,22, o que caracteriza múltipla resistência. O perfil de multirresistência nos três sistemas analisados foi semelhante, sendo que a média dos índices MAR em todos os sistemas foi 0,4. A família Pseudomonadaceae apresentou maior número de amostras resistentes a cinco ou mais antimicrobianos (MAR $>0,44)$, enquanto as outras famílias analisadas apresentaram maior número de bactérias com índice MAR abaixo de 0,44 . Além disso, representantes da família Micrococcaceae não apresentaram resistência simultânea a mais de quatro antimicrobianos.

Tabela 4. Número de populações bacterianas com múltipla resistência a antimicrobianos representantes das diferentes famílias identificadas

\begin{tabular}{ccccccc}
\hline Índice & \multicolumn{5}{c}{ Família bacteriana } & \multirow{2}{*}{ Total } \\
\cline { 2 - 5 } MAR & $\mathrm{E}$ & $\mathrm{M}$ & $\mathrm{P}$ & $\mathrm{V}$ & $\mathrm{NI}$ & 20 \\
\hline 0,22 & 6 & 7 & 1 & 1 & 5 & 32 \\
0,33 & 5 & 10 & 0 & 12 & 5 & 14 \\
0,44 & 2 & 2 & 2 & 5 & 3 & 09 \\
0,55 & 2 & 0 & 5 & 2 & 0 & 12 \\
0,66 & 1 & 0 & 9 & 0 & 2 & 04 \\
0,77 & 0 & 0 & 4 & 0 & 0 & 03 \\
0,88 & 1 & 0 & 0 & 0 & 2 & 94 \\
\hline Total & 17 & 19 & 21 & 20 & 17 & 9 \\
\hline
\end{tabular}

E: Enterobacteriaceae, M: Micrococcaceae, P: Pseudomonadaceae, V: Vibrionaceae, NI: não identificadas. MAR: múltipla resistência antimicrobiana.

\section{DISCUSSÃO}

O estudo de resistência a antimicrobianos de bactérias autóctones permite uma avaliação do seu papel na manutenção e na transferência de genes de resistência a outras bactérias, inclusive patogênicas, a fim de se compreender a disseminação de microrganismos resistentes no ambiente de cultivo do pescado, visto que o ambiente aquático possuiu grande diversidade de espécies bacterianas (Miranda e Zemelman, 2002). Neste trabalho, foram consideradas apenas as famílias bacterianas potencialmente patogênicas para seres humanos e relevantes no que diz respeito ao abrigo e troca de genes de resistência a antimicrobianos. Assim, as famílias descritas são consideradas da microbiota indígena e não indígena dos peixes. Embora bactérias possam estar presentes em baixas contagens iniciais no pescado, algumas condições de processamento e de armazenamento podem levar ao desenvolvimento da população bacteriana, o que constitui um risco para a saúde pública (Huss, 1994). Além disso, a significativa recuperação de membros da família Enterobacteriaceae nos sistemas 1 e 2 sugere que o ambiente de cultivo pode estar contaminado por microrganismos de origem fecal (Miranda e Zemelman, 2001). 
Neste trabalho, a microbiota dos diferentes sistemas de cultivo analisados foi semelhante. Bactérias do gênero Staphylococcus não são comuns no ambiente aquático, porém os fatores que contribuíram para o desenvolvimento destas bactérias nos sistemas analisados, principalmente no sistema 3 , não foram determinados. Os dados sugerem que o adubo pode ter carreado resíduos de antimicrobianos ou determinadas populações de bactérias, que influenciaram a diversidade de espécies bacterianas no sistema 3 .

Estudos prévios, analisando peixes cultivados em tanques com adubação orgânica ou em água contaminada por esgoto humano, mostraram diferenças na composição das espécies bacterianas da microbiota ambiental, sendo mais freqüente, em ambas as condições, o isolamento de membros das famílias Vibrionaceae e Enterobacteriaceae (Miranda e Zemelman, 2001; Petersen e Dalsgaard, 2003b).

Os antimicrobianos testados representam classes de drogas importantes para a terapêutica na medicina humana e na veterinária. A elevada proporção de bactérias resistentes principalmente à ampicilina, à eritromicina e à tetraciclina sugere que outros fatores, além da utilização de antimicrobianos, favorecem a manutenção de bactérias resistentes no ambiente aquático. Antimicrobianos pertencentes ao grupo das tetraciclinas são amplamente utilizados para tratar e prevenir enfermidades na aqüicultura, porém recentemente tem-se observado maior freqüência de isolamento de bactérias resistentes a essa droga oriundas do ambiente aqüícola (Tendência e dela Peña, 2002; Hatha et al., 2005). Além disso, a presença de bactérias resistentes a todos os antimicrobianos testados sugere que, caso haja a utilização de uma droga nos ambientes analisados, essa exercerá uma pressão seletiva que poderá levar à propagação de bactérias resistentes à determinada droga, visto que a transferência de plasmídeos no ambiente de cultivo de peixes é favorecida pela presença de um agente antimicrobiano seletivo (Miranda e Zemelman, 2002).

Outro ponto a ser considerado é que a alta freqüência de bactérias resistentes a antimicrobianos nos sistemas de cultivo 1,2 e 3 levanta a questão sobre a origem dos genes de resistência. Entretanto, este trabalho não determinou se os elementos genéticos que caracterizaram resistência aos antimicrobianos testados são de origem cromossômica ou plasmidial. A resistência a antimicrobianos mediada por plasmídeos já foi relatada em alguns patógenos bacterianos de peixes, como Aeromonas salmonicida, Aeromonas hydrophila, Pseudomonas fluorescens, Edwardsiella tarda, Yersinia ruckeri (Alderman e Hastings, 1998). Caso exista a presença de elementos genéticos móveis nos sistemas de cultivo estudados, estes podem disseminar resistência a antimicrobianos entre espécies bacterianas presentes no ambiente aquático, filogeneticamente distintas, patogênicas ou não. Além disso, os peixes cultivados nesses sistemas podem albergar, sobre a pele e no conteúdo intestinal, bactérias que podem doar genes que codificam mecanismos de resistência às drogas para bactérias patogênicas ou da microbiota de seres humanos.

Em relação ao perfil de resistência a antimicrobianos das famílias bacterianas isoladas dos diferentes sistemas de criação analisados, resultados semelhantes foram obtidos por Hatha et al. (2005), que observaram elevados níveis de resistência à amoxicilina ( $\beta$-lactâmico) e à tetraciclina e de susceptibilidade à gentamicina em Aeromonas sp. isoladas do conteúdo intestinal de peixes de água doce. A resistência da família Vibrionaceae à ampicilina é considerada intrínseca (Schmidt et al., 2001; Radu et al., 2003). Elevada proporção de resistência à ampicilina e de susceptibilidade à gentamicina também foram observadas em bactérias isoladas das brânquias e do conteúdo intestinal de peixes marinhos capturados no Chile (Miranda e Zemelman, 2001).

Há relatos de que a múltipla resistência a antimicrobianos é elevada em ambientes onde há utilização constante de drogas e tem sido observada em bactérias relacionadas ao ambiente aquático (Krumperman, 1983; Miranda e Zemelman, 2002; Hatha et al., 2005). Porém, neste trabalho, os resultados do índice MAR revelaram que, mesmo na ausência de antimicrobianos nos sistemas de cultivo analisados, a maioria das amostras bacterianas foi considerada fontes de alto risco para disseminação de genes de resistência.

Plasmídeos podem carrear determinantes de resistência simultânea a várias drogas, o que pode levar ao fenômeno de seleção cruzada 
aumentando o número de bactérias multirresistentes em determinado ambiente (McPhearson et al., 1991). Além disso, a transferência de plasmídeos que codificam determinantes de resistência a múltiplas drogas entre bactérias patogênicas de seres humanos, de animais e de peixes e bactérias susceptíveis isoladas de outros nichos ecológicos já foi relatada (Kruse e Sorum, 1994). Mutações no cromossomo bacteriano também estão relacionadas com a múltipla resistência a antimicrobianos, pois podem codificar sistemas de efluxo que impedem o acúmulo de diversos antimicrobianos no interior da célula bacteriana (Miranda e Zemelman, 2002). Assim, como foi observada porcentagem significativa de bactérias com resistência simultânea a algumas drogas nos sistemas de cultivo analisados, sugere-se que pode estar havendo a disseminação de elementos genéticos móveis ou a seleção de amostras mutantes. Apesar de este estudo não permitir avaliar se o perfil de multirresistência das amostras testadas se deve a mutações cromossômicas, plasmídeos ou outros elementos genéticos móveis, as bactérias isoladas dos sistemas de cultivo 1,2 e 3 podem ser consideradas fontes de alto risco para manutenção e disseminação de resistência a múltiplas drogas.

A transferência de múltipla resistência a antimicrobianos é um dos principais problemas decorrentes do uso de antimicrobianos na aqüicultura, visto que a pressão de seleção favorece as trocas de genes de resistência entre bactérias do ambiente (Miranda e Zemelman, 2002). A presença, portanto, de grande número de bactérias resistentes e multirresistentes no ambiente aquático gera implicações ecológicas e de saúde pública e enfatiza a necessidade de novos estudos, principalmente em relação aos determinantes de resistência em diferentes espécies bacterianas, assim como sobre a possibilidade de transferência de genes de resistência a patógenos humanos mediante $\mathrm{o}$ consumo de pescado (Miranda e Zemelman, 2001). Os dados obtidos sugerem que outros fatores, além da utilização de antimicrobianos na aqüicultura, favorecem a manutenção e a disseminação de bactérias resistentes a antimicrobianos em diferentes ambientes de cultivo de pescado. Além disso, o tipo de sistema de cultivo de tilápia-do-nilo não influenciou o perfil qualitativo de resistência bacteriana a antimicrobianos.

\section{REFERÊNCIAS BIBLIOGRÁFICAS}

ALDERMAN, D.J.; HASTINGS, T.S. Antibiotic use in aquaculture: development of antibiotic resistance - potential for consumer health risks. Int. J. Food Sci. Technol., v.33, p.139-155, 1998.

ALI ABADI, F.S.; LEES, P. Antibiotic treatment for animals: effect on bacterial population and dosage regimen optimization. Int. J. Antimicrob. Agents, v.14, p.307-313, 2000.

BRUUN, M. S.; MADSEN, L.; DALSGAARD, I. Efficiency of oxytetracycline treatment in rainbow trout experimentally infected with Flavobacterium psychrophilum strains having different in vitro antibiotic susceptibilities. Aquaculture, v.215, p.11-20, 2003.

BUTAYE, P.; CLOECKAERT, A.; SCHWARZ, S. Mobile genes coding for efflux-mediated antimicrobial resistance in Gram-positive and Gram-negative bacteria. Int. J. Antimicrob. Agents, v.22, p.205-210, 2003.

HARRIGAN, W. F. (Ed). Laboratory methods in food microbiology. 3.ed. San Diego: Academic, 1998.

HATHA, M.; VIVEKANANDHAN, A.A.; JOICE, G. J. et al. Antibiotic resistance pattern of motile aeromonads from farm raised fresh water fish. Int. J. Food Microbiol., v.98, p.131134, 2005.

HÖLMSTROM, K.; GRÄSLUND, S.; WAHLSTRÖM, A. et al. Antibiotic use in shrimp farming and implications for environmental impacts and human health. Int. J. Food Sci. Technol., v.38, p.255-266, 2003.

HUSS, H .H. Assurance of seafood quality. Roma:FAO, 1994. 169p. (Technical Paper $\mathrm{n}^{\mathrm{o}}$ 334).

KRUMPERMAN, P.H. Multiple antibiotic resistance indexing of Escherichia coli to identify high-risk sources of fecal contamination of foods. Appl. Environ. Microbiol., v.46, p.165$170,1983$.

KRUSE, H.; SORUM, H. Transfer of multiple drug resistance plasmids between bacteria of diverse origins in natural microenvironments. 
Appl. Environ. Microbiol., v.60, p.4015-4021, 1994.

McPHEARSON, R.M.; DEPAOLA, A.; ZYWNO, S.R. et al. Antibiotic resistance in Gram-negative bacteria from cultured catfish and aquaculture ponds. Aquaculture, v.99, p.203-211, 1991.

MIRANDA, C.D.; ZEMELMAN, R. Antibiotic resistant bacteria in fish from Concepción Bay, Chile. Mar. Poll. Bull., v.42, p.1096-1102, 2001.

MIRANDA, C.D.; ZEMELMAN, R. Antimicrobial multiresistance in bacteria isolated from freshwater Chilean salmon farms. Sci. Total Environ., v.293, p.207-218, 2002.

NOGA, E. J. (Ed). Fish disease: diagnostic and treatment. St. Louis: Mosby, 1996. 367p.

OSTRENSKY, A.; BOEGER, W.A. Piscicultura : fundamentos e técnicas de manejo. Guaíba: Agropecuária, 1998. 211p.

PERFORMANCE standards for antimicrobial disk susceptibility tests. 4.ed. Villanova, USA: NCCLS, 1990. (Document M2-A4).

PETERSEN, A.; ANDERSEN, J.S.; KAEWMAK, T. et al. Impact of integrated fish farming on antimicrobial resistance in a pond environment. Appl. Environ. Microbiol., v.68, p.6036-6042, 2002.

PETERSEN, A.; DALSGAARD, A. Antimicrobial resistance of intestinal Aeromonas spp. and Enterococcus spp. in fish cultured in integrated broiler-fish farms in Thailand. Aquaculture, v.219, p.71-82, 2003a.

PETERSEN, A.; DALSGAARD, A. Species composition and antimicrobial resistance genes of Enterococcus spp., isolated from integrated and traditional fish farms in Thailand. Environ. Microbiol., v.5, p.395-402, 2003 b.
QUINN, P.J.; CARTIER, M.E.; MARKEY, B. Clinical veterinary microbiology. London: Wolfe, 1994, 648p.

RADU, S.; AHMAD, N.; LING, F.H.; et al. Prevalence and resistance to antibiotics for Aeromonas species from retail fish in Malasya. Int. J. Food Microbiol., v.81, p.261-266, 2003.

RHODES, G.; HUYS, G.; SWINGS, J.; et al. Distribution of oxytetracycline resistance plasmids between aeromonads in hospital and aquaculture environments: implication of Tn1721 in dissemination of the tetracycline resistance determinant Tet A. Appl. Environ. Microbiol., v.66, p.3883-3890, 2000.

RIVERA-TAPIA, J.A. Antibiotic resistance, public health problem. An. Med. Hosp. ABC. v.48, p.42-47, 2003.

SCHMIDT, A.S.; BRUUN, M.; DALSGAARD, I. et al. Incidence, distribuition, and spread of tetracycline resistance determinants and integron-associated antibiotic resistance genes among motile aeromonads from a fish farming environment. Appl. Environ. Microbiol., v.67, p.5675-5682, 2001.

SORUM, H.; ABÉE-LUND, T.M. Antibiotic resistance in food-related bacteria - a result of interfering with the global web of bacterial genetics. Int. J. Food Microbiol., v.78, p.43-56, 2002.

TENDENCIA, E.A.; dela PEÑA, D.P. Level and percentage recovery of resistance to oxitetracycline and oxolinic acid of bacteria from shrimp ponds. Aquaculture, v.213, p.1-13, 2002.

WEGENER, H.C.; MOLLER, N.F. Reducing the use of antimicrobial agents in animals and man. J. Med. Microbiol., v.49, p.111-113, 2000. 